\title{
A pandemia da COVID-19 e a utilização dos parques públicos urbanos de
}

\section{Garanhuns - PE}

\author{
The COVID-19 pandemic and the use of urban public parks in Garanhuns - PE \\ La pandemia de COVID-19 y el uso de parques públicos urbanos em Garanhuns - PE
}

Isabelle Maria Magalhães Paiva

ORCID: https://orcid.org/0000-0001-7899-7697

Universidade Federal Rural de Pernambuco, Brasil E-mail: Isabelle.paiva3105@gmail.com

Luciano Pires de Andrade

ORCID: https://orcid.org/0000-0001-5818-711X

Universidade Federal Rural de Pernambuco, Brasil E-mail: Luciano.andrade@ufape.edu.br

Horasa Maria Lima da Silva Andrade

ORCID: https://orcid.org/0000-0002-5366-6610

Universidade Federal Rural de Pernambuco, Brasil E-mail: horasa.andrade@ufape.edu.br

Romário Nunes da Silva

ORCID: https://orcid.org/0000-0002-0401-8000

Universidade Federal Rural de Pernambuco, Brasil E-mail: romario.nuness@gmail.com

\begin{abstract}
Resumo
O objetivo da pesquisa foi identificar a situação atual do uso e função dos parques durante o período de pandemia da COVID-19 através do uso do mapa comportamental centrado nos lugares, em dois parques urbanos de Garanhuns PE. Sabendo que o mapa comportamental é importante para a compreensão das relações entre o ambiente e o comportamento de áreas livres, pois fornecem um retrato dos diversos tipos de comportamentos e suas frequências, realizou-se observações no período da manhã e da tarde, a fim de comparar a utilização do espaço nesses dois período. A partir do percurso preestabelecido criou-se os pontos de observação, que resultou em mapas comportamentais das atividades que estavam acontecendo no ambiente e o tipo de usuário encontrado no momento de observação. A partir da análise realizada nos parques em estudo, foi possível identificar 06 categorias de usuários, as quais estão relacionadas com a faixa etária e atividade realizada no local. Percebeu-se que os parques tem funções, público e atividades diferentes, devido aos equipamentos presentes em seu interior, também foi detectado que existe a falta de cuidado com um dos parques, visto que foi identificado a falta de manutenção em alguns equipamentos.
\end{abstract}

Palavras-chave: Área verde; COVID-19; Lazer; Mapa comportamental.

\begin{abstract}
The objective of the research was to identify the current situation of the use and function of parks during the COVID19 pandemic period through the use of a behavioral map centered on places, in two urban parks in Garanhuns - PE. Knowing that the behavioral map is important for understanding the relationship between the environment and the behavior of free areas, as they provide a picture of the different types of behavior and their frequencies, observations were carried out in the morning and afternoon, in order to compare the use of space in these two periods. From the pre-established route, observation points were created, which resulted in behavioral maps of the activities that were taking place in the environment and the type of user found at the time of observation. From the analysis carried out in the parks under study, it was possible to identify 06 categories of users, which are related to the age group and activity performed at the site, it was noticed that the parks have different functions, public and activities, due to the equipment present. inside, it was also detected that there is a lack of care with one of the parks, since the lack of maintenance in some equipment was identified.
\end{abstract}

Keywords: Green area; COVID-19; Leisure; Behavioral map.

\section{Resumen}

El objetivo de la investigación fue identificar la situación actual del uso y función de los parques durante el período pandémico del COVID-19 mediante el uso de un mapa conductual centrado en lugares, en dos parques urbanos de Garanhuns - PE. Sabiendo que el mapa de comportamiento es importante para comprender la relación entre el entorno y el comportamiento de las áreas libres, ya que brindan una imagen de los diferentes tipos de comportamiento y sus frecuencias, se realizaron observaciones por la mañana y por la tarde, con el fin de comparar el uso del espacio en 
estos dos períodos. A partir de la ruta preestablecida, se crearon puntos de observación, que resultaron en mapas de comportamiento de las actividades que se estaban realizando en el entorno y el tipo de usuario encontrado en el momento de la observación. A partir del análisis realizado en los parques en estudio, fue posible identificar 06 categorías de usuarios, los cuales se relacionan con el grupo de edad y actividad que se realiza en el sitio, se notó que los parques tienen diferentes funciones, público y actividades, debido a los equipos presentes en el interior, también se detectó que existe un descuido con uno de los parques, ya que se identificó la falta de mantenimiento en algunos equipos.

Palabras clave: Area verde; COVID-19; Ocio; Mapa de comportamiento.

\section{Introdução}

O início da história dos parques urbanos ocorreu com propósito paisagístico, surgindo na Inglaterra no final do século XVIII, cem anos mais tarde os parques surgiram novamente, mas com a consequência da nova cidade industrial, que passou a existir com a revolução industrial do século XIX (Macedo \& Sakata, 2003).

Já no Brasil, os parques urbanos não surgem da urgência social das massas urbanas do século XIX, pois o país não apresentava as mesmas características dos países europeus, não possuindo nenhuma cidade com população ou área equivalente, desta forma, o parque foi criado pretendendo desenvolver um cenário próximo ao que as elites brasileiras viam na Europa, principalmente na Inglaterra e França (Macedo \& Sakata, 2010).

Na Lei n. 9.985/00, do Sistema Nacional de Unidades de Conservação (SNUC), a definição de parque está relacionada ao conceito de Unidades de Conservação (UC) de proteção integral, seja em perímetro urbano ou rural, seja de gestão federal, estadual ou municipal. A criação desses parques tem a proposição de preservar o meio ambiente e a qualidade de vida das populações que habitam no entorno dessas áreas (Brasil, 2000).

Carneiro e Mesquita (2000) definem parques da seguinte forma:

São espaços livres públicos com função predominante de recreação, ocupando na malha urbana uma área em grau de equivalência superior à da quadra típica urbana, em geral apresentando componentes da paisagem natural - vegetação, topografia, elemento aquático - e edificações destinadas a atividades recreativas, culturais e/o administrativas.

Barcellos (2000) afirma que os parques urbanos têm como função combater as mazelas urbanas causadas pela revolução industrial, tendo como objetivo ser um espaço que encoraje interação, relaxamento e prazer aos arredores do parque. Dessa forma, os parques urbanos vêm sendo reconhecido como um determinante chave da saúde, Kothcencz \& Blascke (2017) relatam que esses ambientes são contribuintes essenciais para a qualidade de vida urbana.

Sabendo que os parques urbanos podem trazer qualidade de vida para a população, através do contato com a natureza e suas estruturas e qualidade ambiental que, quando adequadas e atrativas, são determinantes para a realização de atividade física e o lazer, gerando benefícios psicológicos, sociais e físicos a saúde dos indivíduos, como, por exemplo, a redução do sedentarismo e amenizar o estresse do cotidiano urbano (Szeremeta \& Zannin, 2013).

No entanto, o ano de 2020 marcou a história da humanidade devido à grave crise sanitária causada pela COVID-19, que pela Organização Mundial de Saúde (OMS) é um vírus conhecido como causador de resfriados nos seres humanos, que, segundo a maioria da comunidade científica surgiu na China. $\mathrm{O}$ sentimento de medo e perplexidade foi crescendo à medida que a situação indicava a emergência de uma pandemia, atingindo novos países e causando perdas de milhares de vida (Pimentel \& Silva, 2020; Silva et al., 2021).

Em muitas partes do mundo, as preocupações com a pandemia da COVID-19 e a política de quarentena das cidades levaram a um declínio geral na saúde física e mental dos moradores devido à falta de interação social (Xie et al., 2020). Em termos de saúde mental, acredita-se que as medidas durante a quarentena causaram pânico e medo entre os moradores urbanos (Kamara et al., 2017). 
Com a propagação da doença a partir de dezembro de 2019, as cidades tiveram que adotar emergencialmente planos de enfretamento ao longo do ano de 2020, que incluíam a suspensão de aglomerações e a redução ao mínimo de toda as atividades que exigem contato social: comércio, serviços, cultura, lazer e até mesmo acessos aos serviços de saúde, entre outros (Ximenes et al., 2020).

Porém, os efeitos deletérios do confinamento na saúde mental foram mais acentuados nas cidades, em comunidades socialmente desfavorecidas e entre grupos demográficos vulneráveis, como crianças e idosos. Sabe-se que a utilização e contato com espaços verdes urbanos e outros espaços naturais é essencial para reduzir o stress causado pelo confinamento, além de proporcionar oportunidades de relaxamento, promovendo a resiliência urbana (Tendais \& Ribeiro, 2020).

E atualmente a importância dos parques para a vida urbana é evidenciada, pois as cidades começam a retomar as atividades pós-isolamento, e a população está correndo para os parques (Paula \& Caser, 2020). Assim, a necessidade de preparar-se para eventos futuros vem levando cidades de todo o mundo a elaborarem e implementarem suas estratégias de resiliência (Ventura et al., 2021). Pois um número crescente de investigações tem demonstrado que o contato físico e/ou visual com espaços verdes está associado a melhores indicadores de saúde mental, designadamente menores níveis de ansiedade (Triguero-MAS et al., 2017), menor risco de depressão (Gascon et al., 2018), menores níveis de marcadores biológicos de estresse (Ribeiro et al., 2019).

Dessa forma, os mapas comportamentais fornecem um retrato dos diversos tipos de comportamentos e suas frequências, sendo extremamente úteis para a compreensão das relações entre ambiente e comportamento de áreas livres públicas, praças, hotéis, locais com grande concentração de usuários e atividades distintas (Cunha et al., 2016).

Neste cenário, o objetivo desta investigação foi realizar um mapa comportamental centrado nos lugares, em dois parques urbanos de Garanhuns - PE para identificar a situação atual do uso e função dos equipamentos pela população durante o período de pandemia da COVID-19.

\section{Metodologia}

O mapa comportamental é importante para a compreensão das relações entre o ambiente e o comportamento de áreas livres, pois fornecem um retrato dos diversos tipos de comportamentos e suas frequências. De acordo com Rheingantz et al. (2009) o mapa comportamental é um instrumento para registro das observações sobre o comportamento e as atividades dos usuários em um determinado ambiente. Com isso, através desse método é possível entender que são os usuários do espaço, o que eles fazem, com quem e como interagem, e de que forma utilizam o espaço.

Existem dois tipos de mapas comportamentais, os centrados nos lugares e centrados nos indivíduos. Nos mapas centrados nos lugares, os observadores ficam parados em um ou mais pontos estratégicos, registrando em desenhos préelaborados do local todos os movimentos e ações que nele ocorrem (Rheingantz et al., 2009).

O município de Garanhuns-PE possui uma população estimada de 140.577 habitantes de acordo com o IBGE (2020), com temperatura média anual de $21^{\circ} \mathrm{C}$, com variação de $15^{\circ}$ a $30^{\circ} \mathrm{C}$, e fica a $230 \mathrm{~km}$ da capital Recife. Para a realização da pesquisa foi selecionado o Parque Euclides Dourado, com área de $92.731,40 \mathrm{~m}^{2}$, que está localizado no bairro Heliópolis, na Av. Júlio Brasileiro, e o Parque Ruber Van Der Linden, com área de 10.999,60m², localizado no bairro Santo Antônio, na R. Manoel Clemente (Figura 1). 
Figura 1 - Localização dos locais em estudo no município de Garanhuns- PE.

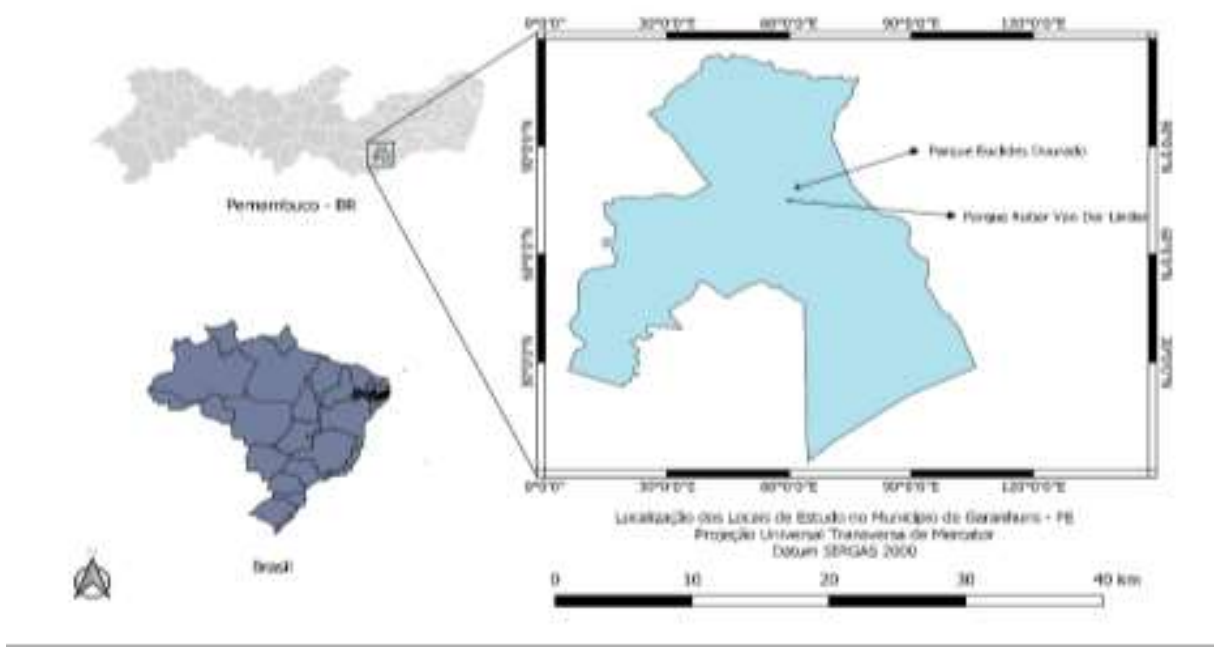

Fonte: Autores (2021).

As observações para o desenvolvimento dos mapas comportamentais foram realizadas no período diurno - das $08 \mathrm{~h} 30$ às $12 \mathrm{~h} 00 \mathrm{e}$ das $14 \mathrm{~h} 00$ às $17 \mathrm{~h} 00$, a fim de comparar a utilização do espaço nesses dois períodos. Os levantamentos no Parque Euclides Dourado (Figura 2-A) ocorreram nos dias 19, 20 e 21 de maio de 2021, (quarta-feira, quinta-feira e sexta-feira) e no Parque Ruber Van Der Linden (Figura 2-B) nos dias 25, 26 e 27 de junho de 2021, (sexta-feira, sábado e domingo).

Figura 2 - Parque Euclides Dourado e Parque Ruber Van Der Linde, Garanhuns-PE.

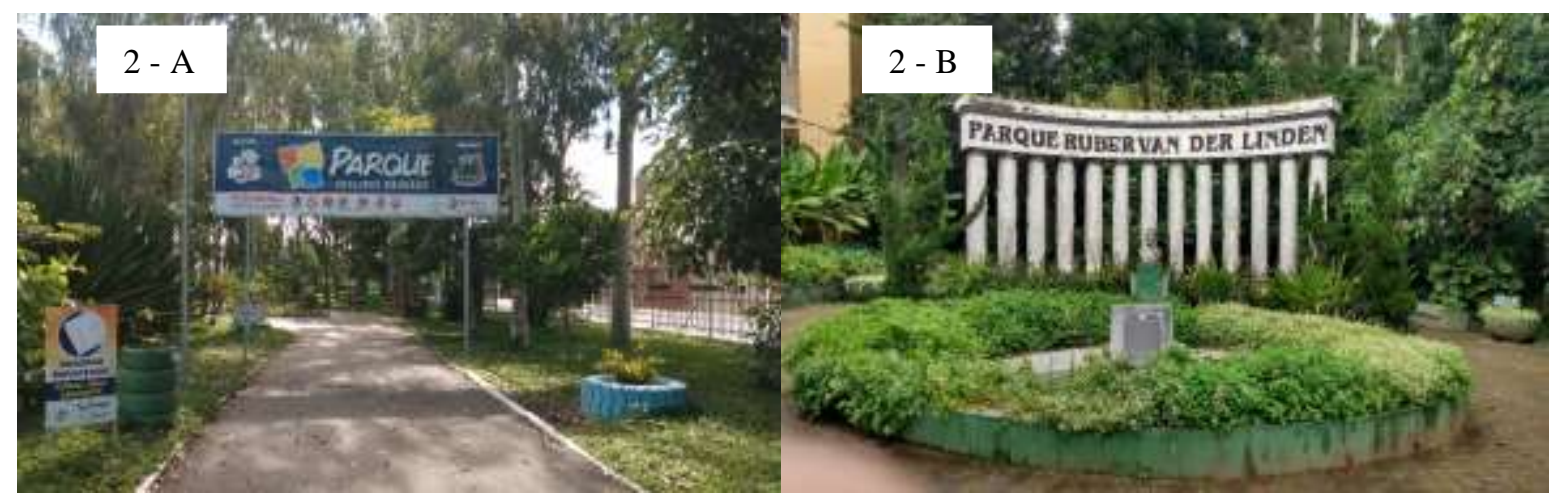

Fonte: Autores (2021).

As observações foram feitas a partir de um percurso preestabelecido a fim de percorrer todo o parque, utilizando o Google Earth para imprimir os trechos dos parques e definir os pontos de observação, sendo considerado 10 minutos de observação em cada um desses pontos para que pudesse ser registrado as atividades e comportamentos das pessoas.

A aplicação dessa metodologia resultou em mapas comportamentais com marcação das atividades e do tipo de usuário encontrado nos momentos das observações. Os mapas comportamentais individuais, aplicados em cada dia foram combinados em um único mapa composto, mostrando a ocupação e a forma de utilização dos espaços do parque durante a manhã e tarde.

Com o objetivo de tornar graficamente mais legíveis as informações obtidas nos mapas comportamentais, foi realizado mapas de atividade, ou seja, com pessoas paradas, sentadas, conversando ou apenas contemplando a paisagem, e em movimento, que se enquadra as pessoas que estão caminhando e praticando atividade física, através de manchas e símbolos de fluxo que são coloridas de acordo com o fluxo de usuários observados no local. O critério definido para delimitar os espaços com atividade e movimento intenso, moderado e pouco foi através do fluxo de frequentadores durante a aplicação do mapa, 
sendo de 1 a 10 fluxo baixo, 11 a 20 fluxo médio e a partir de 21 fluxo intenso.

A realização desta investigação só foi possível graças ao apoio financeiro da Coordenação de Aperfeiçoamento de Pessoal de Nível Superior - CAPES com a concessão de uma bolsa de pesquisa.

\section{Resultados e Discussão}

A análise dos mapas comportamentais no Parque Euclides Dourado e Parque Ruber Van Der Linden, resultou na identificação de 06 categorias de usuários, as quais estão relacionadas com a faixa etária e atividade realizada no local, percebeu-se que existe um intenso e variado uso e público nos espaços dos parques.

Quanto a localização, o Parque Ruber Van Der Linden se encontra sobre uma encosta, nele está presente uma grande diversidade arbórea, possuindo função ambiental e ecológica de forma marcante, nele existe a possibilidade para crianças praticarem lazer ativo, no entanto, o parque não possui equipamentos destinados ao lazer dos adultos, e devido a vegetação intensa, acaba fazendo com o que ocorra uma baixa iluminação durante o final da tarde, fazendo com que o seu funcionamento ocorre até as dezessete horas.

Com relação aos acessos no interior do parque, a maior parte dele é através de escadarias ou vias inclinadas com piso de paralelepípedos, dificultando o acesso a pessoas que necessitam de acessibilidade, como cadeirantes, idosos e até mesmo crianças pequenas, vale ressaltar que durante o período de pandemia da COVID-19, tornou-se obrigatório o uso da máscara no interior do parque (Figura 3).

Figura 3 - Vias de acesso no interior do Parque Ruber Van Der Linden, Garanhuns-PE.

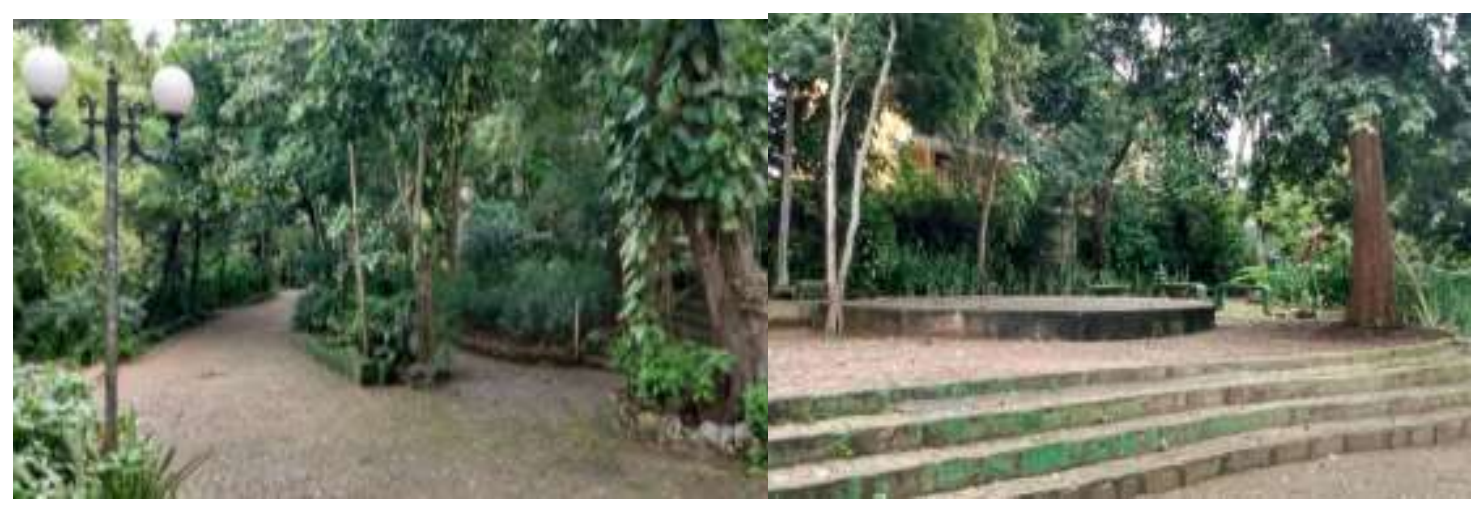

Fonte: Autores (2021).

Em relação ao público que frequenta o parque, verificou-se que acontece encontro de casais e amigos de todas as idades, crianças com a presença dos pais, adultos adaptando locais do parque para praticar atividade física, turistas, idosos passeando e pessoas contemplando a paisagem. Vale ressaltar que antes da pandemia da COVID-19, o parque recebia muitos estudantes nos horários da manhã e à tarde, por estar localizados próximo de instituições de ensino.

Durante o período da coleta de dados no parque o decreto municipal estava mais flexível, devido ao número reduzido de pessoas contaminadas pelo vírus, o funcionamento do parque estava acontecendo durante a semana e aos finais de semana, no entanto, o restaurante e as barracas de artesanato que existem em seu interior não estavam funcionando, além de vários locais que foram isolados como forma de controle de pessoas nos ambientes.

Observou-se também que o parque não realizou nenhuma adaptação como forma de evitar a contaminação dos usuários que frequentam o parque, apenas colocaram uma faixa de aviso sobre a importância do uso da máscara na entrada do parque e fecharam a entrada principal como forma de controle da quantidade de pessoas que entram no local. Notou-se também que o parque está bastante abandonado em relação a reformas, visto que existe ambientes que estão esquecidos e sem 
cuidados (Figura 4). No estudo de Liberalino (2011) na praça Kalina Maia, traços de indicativo de ausência de manutenção constante também foram encontrados, visto que foram registrados a presença de erosão, bancos arrancados, pisos quebrados, embalagens de comprimidos, seringas, roupas, grafites e escritas em mesas dos caramanchões e equipamentos em concreto da praça.

Figura 4 - Exemplos de ambientes que estão sem cuidados no interior do parque.

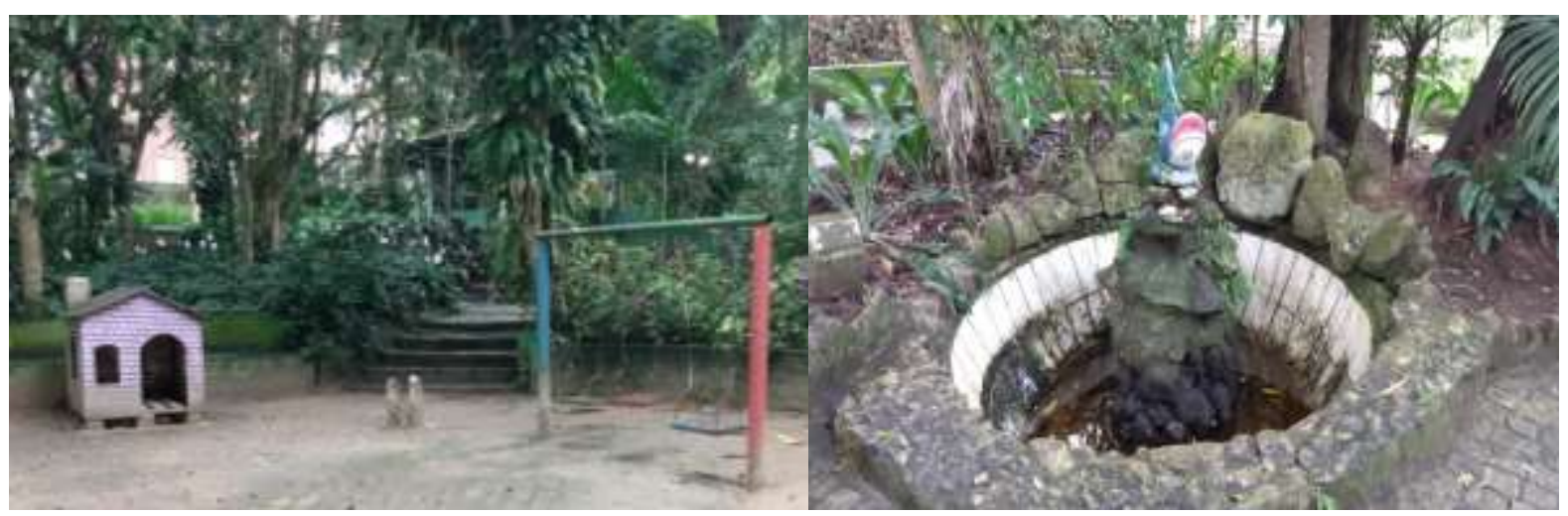

Fonte: Autores (2021).

Enquanto no período de coleta de dados no Parque Euclides Dourado, o seu funcionamento estava acontecendo em dias e horários reduzidos, devido ao decreto municipal que estava mais rigoroso, o seu funcionamento estava acontecendo de segunda-feira a sexta-feira, no horário de $06 \mathrm{~h} 00$ as $17 \mathrm{~h} 00$, sendo necessário o uso da máscara pelos frequentadores, vale destacar que o parque realizou adaptações desde a sua entrada até o seu interior, dispondo de uma equipe verificando a temperatura dos frequentados e oferecendo álcool 70\%, faixas com avisos sobre a importância do uso da máscara na entrada e espalhadas no interior do parque, além de pias para a lavagem das mãos (Figura 5).

Figura 5 - Adaptações realizadas no interior do Parque Euclides Dourado, Garanhuns-PE.

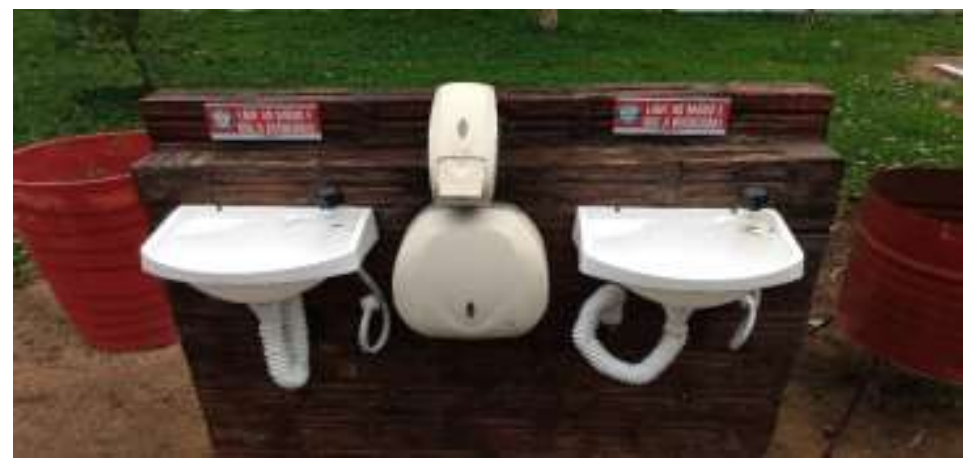

Fonte: Autores (2021).

Percebeu-se que no parque Euclides Dourado existe uma maior diversidade de lazer, devido aos equipamentos de uso social presentes no local, que possibilitando que ocorra o lazer ativo para todas as idades, através das quadras poliesportivas, pista de cooper, playground, pista de skate, equipamentos de academia e alongamentos para exercícios físicos e bancos espalhados pelo parque, além da presença de banheiros, quiosques no interior do parque que contribui para permanência dos frequentadores por tempo prolongado (Figura 6). 
Figura 6 - Diversidade de áreas para lazer no Parque Euclides Dourado, Garanhuns - PE.

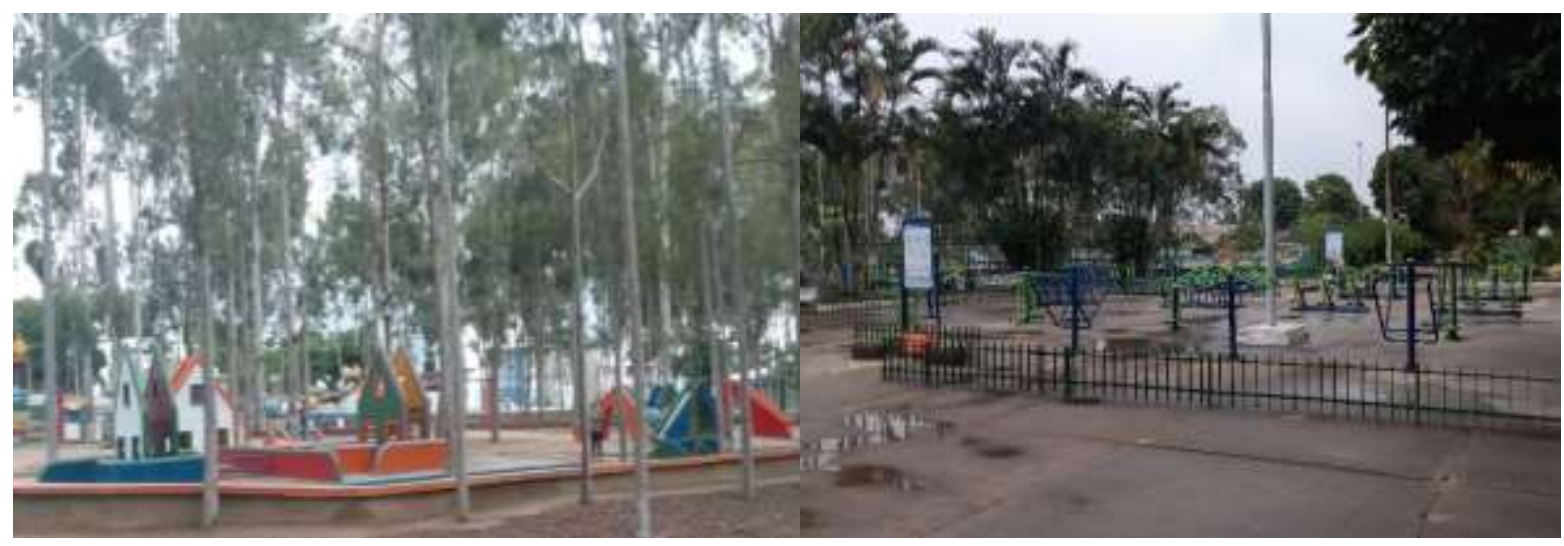

Fonte: Autores (2021).

As quadras poliesportivas e a pista de skate não são muito usadas durante a semana, o uso ocorre com mais frequência no período da tarde por adolescentes e adultos, vale ressaltar que durante o período de pandemia da COVID-19, as quadras poliesportivas ficaram sem funcionar, como forma de evitar a aglomeração de pessoas.

A biblioteca pública e o planetário presentes no parque possibilita que aconteça atividades educacionais, pois através deles é possível que ocorra visitas de grupos de estudantes, passeios escolares, além de ser um espaço para estudos, porém, durante a pandemia também foi necessário parar o funcionamento desses espaços. A academia do parque estava sendo liberada apenas para frequentadores cadastrados, como forma de controle e evitando aglomeração no local, as aulas estavam acontecendo no início da manhã e ao final da tarde.

A análise dos mapas comportamentais do Parque Euclides Dourado, resultou na identificação de 06 categorias de usuários, as quais estão relacionadas com a faixa etária e atividade realizada no local. Assim, percebeu-se que existe um intenso e variado uso dos espaços do parque durante a tarde, enquanto durante a manhã é menos intenso (Figura 7). 
Figura 7 - Mapa comportamental durante a manhã e à tarde no Parque Euclides Dourado.
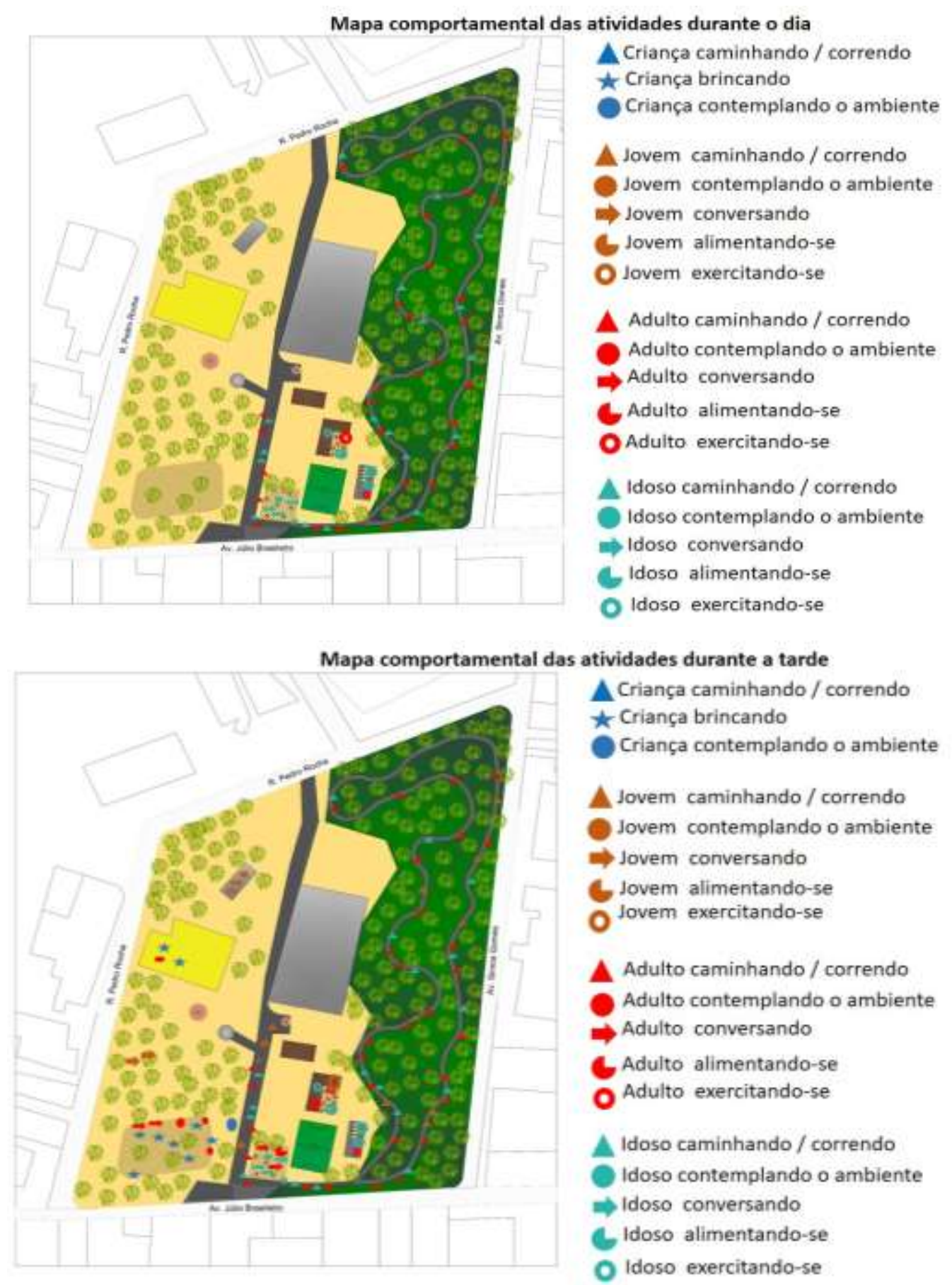

Fonte: Autores (2021).

A partir da análise para a realização do mapa comportamental, constatou-se que no período da manhã os usuários encontrados em maior quantidade nos espaços do parque são adultos e idosos, enquanto no período da tarde os usuários encontrados são as crianças, os jovens, adultos e idosos. Observou-se que os adultos e os idosos utilizam o parque na mesma intensidade durante a manhã e à tarde, enquanto as crianças não foram registrados durante a manhã no parque, e os jovens foram vistos apenas no horário da tarde.

Nos mapas de fluxos de movimento, percebeu-se que durante o dia as zonas de maior atividade e movimento se localizam em pontos importantes da praça (academia ao ar livre, pista de cooper, mesas e aparelhos para alongamento), os locais com baixo fluxo de movimento se encontra no campo de futebol, playground e na pista de Skate, enquanto durante a 
tarde as zonas de maior movimento se localizam na pista de cooper, academia ao ar livre, playground, mesas, aparelho para ginastica e pista de Skate, e o campo de futebol permanece com baixo fluxo, visto que as quadras poliesportivas estavam com uso restrito devido a pandemia da COVID-19 (Figura 8). Resultados semelhantes foi encontrado no estudo de Paula (2017) no Parque da Cidade, verificou-se que ele é bem utilizado em alguns horários específicos e que as práticas de atividade física, com destaque para a pista de caminhada/corrida é bastante concorrida tanto por homens quanto por mulheres, na maioria adultos e poucos idosos, além da pista, os aparelhos da academia também costuma atrair muitas pessoas.

Figura 8 - Mapa comportamental do movimento durante o dia no Parque Euclides Dourado.
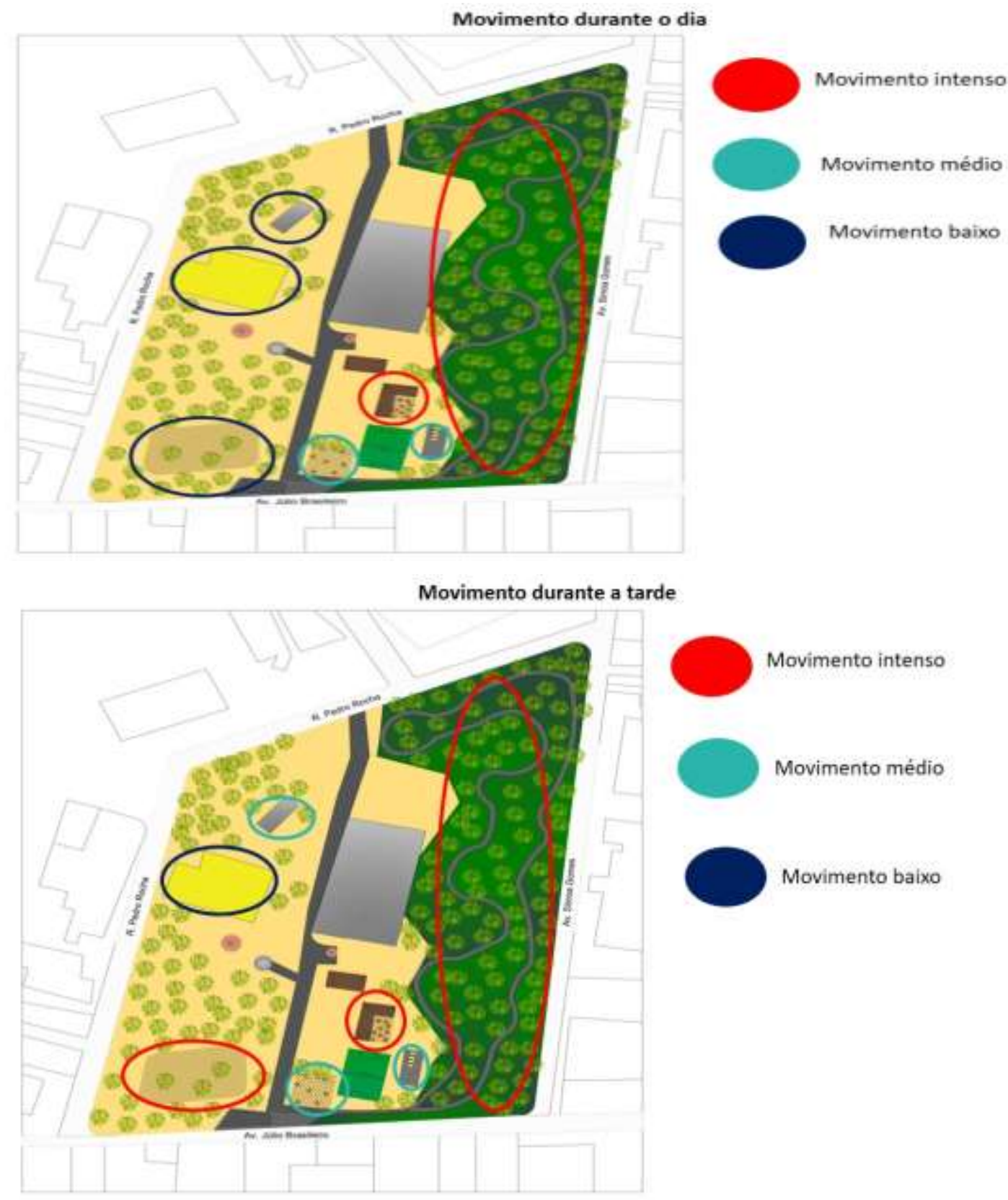

Fonte: Autores (2021).

Com relação a forma de utilização dos espaços do parque Euclides Dourado, o mapa comportamental demonstrou que, tanto durante o dia como durante a tarde, os frequentadores utilizam o parque em praticamente toda a sua extensão de forma e intensidade diferente de acordo com o tipo de atividade que o espaço proporciona. 
No parque Ruber Van Der Lindem, verificou-se a predominância de 04 categorias de usuários (Figura 9), além disso, percebeu-se que o público que utiliza o local é em sua maioria os turistas, e por não ser um parque onde é possível praticar atividade física e com um playground pequeno e esquecido, a população local utiliza com menos frequência.

Figura 9 - Mapa comportamental durante a manhã e à tarde no Parque Ruber Van Der Linden.

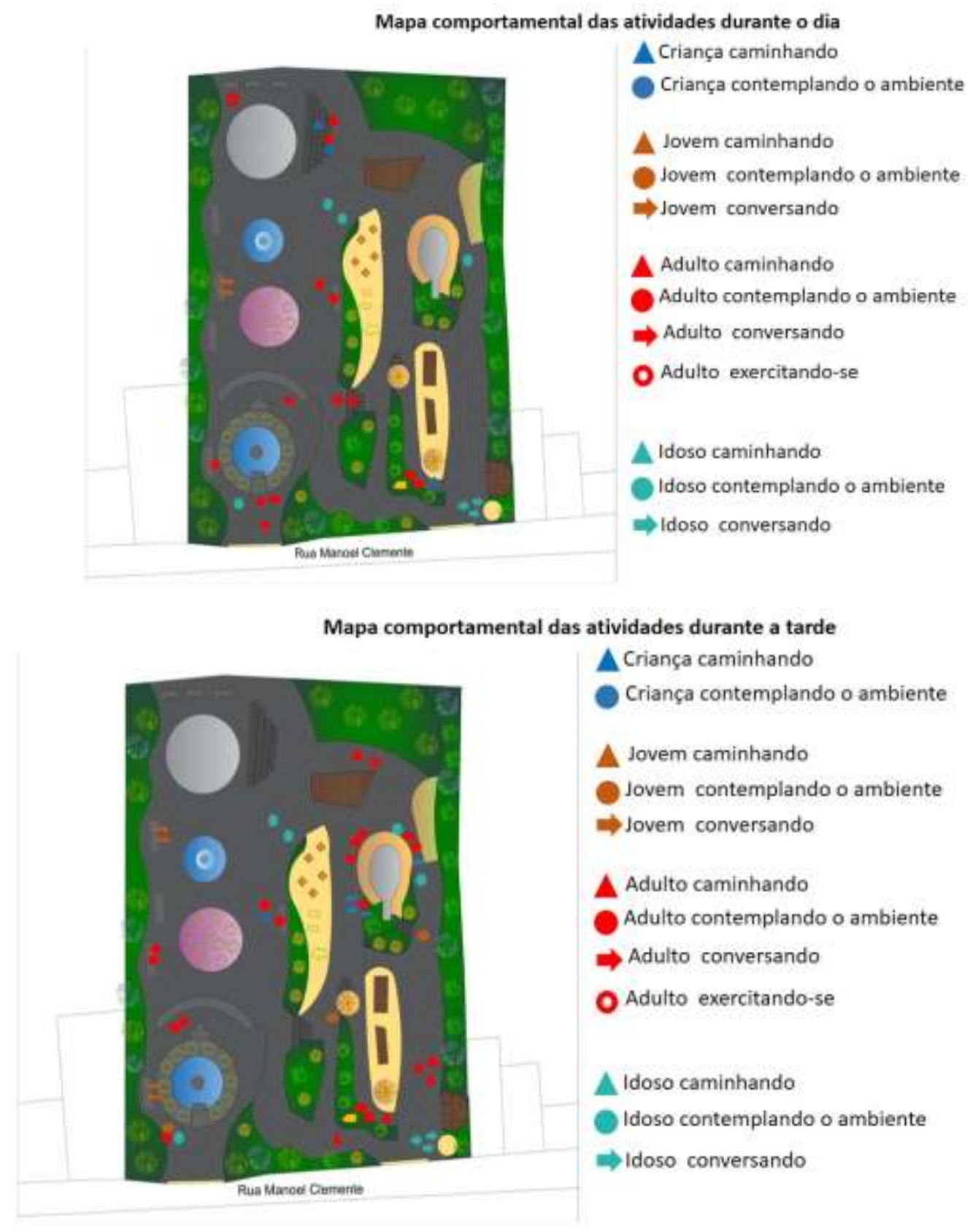

Fonte: Autores (2021).

Em relação ao fluxo de movimento no parque, percebeu-se que está localizado em locais específicos, como por exemplo, na parte frontal do parque, onde se encontra a entrada convidativa do parque, no pavilhão Euclides Dourado e nos viveiros de animais, e por não ser um parque de lazer, as pessoas estão em constante movimento, contemplando a natureza presente no ambiente (Figura 10). 
Figura 10 - Mapa comportamental do movimento durante a manhã e à tarde no Parque Ruber Van Der Linde, Garanhuns-PE.

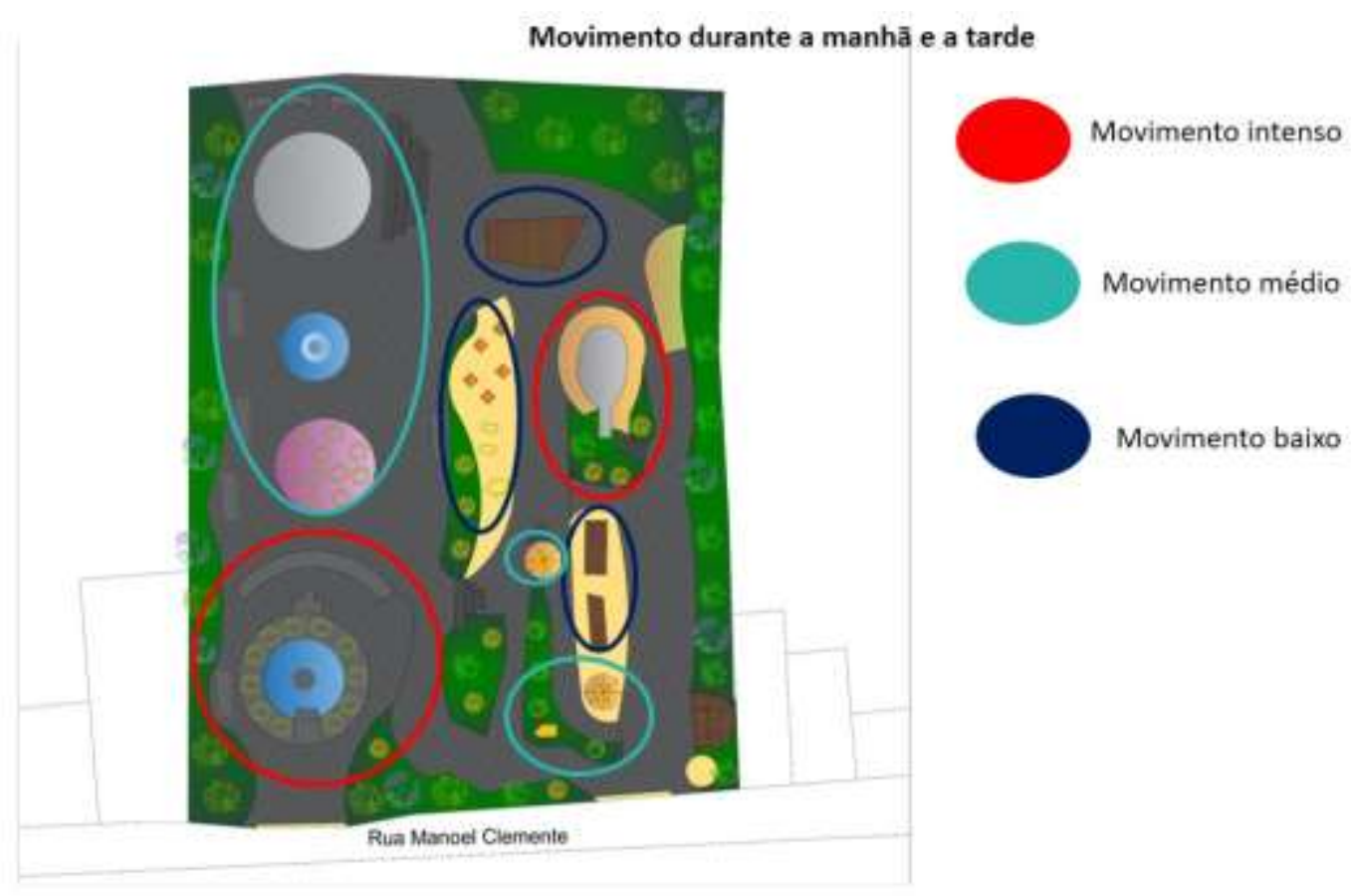

Fonte: Autores (2021).

Quanto a faixa etária dos frequentadores do parque, percebeu-se que durante a manhã e tarde o público é bastante variado, visto que grande parte dos frequentadores são visitantes em grupo, famílias e casais, ou seja, houve a predominância de jovens, adultos, idosos e crianças em ambos os horários.

\section{Conclusão}

Portanto, a metodologia utilizada nesta pesquisa se mostrou eficiente para o mapeamento e análise do uso dos parques urbanos durante o período da pandemia da COVID-19, principalmente por se tratar de uma metodologia rápida, sendo contributiva ao cronograma estabelecido para o desenvolvimento do estudo. Os resultados obtidos permitiram constatar que mesmo diante de tantas incertezas, os parques urbanos estavam contribuindo para a população durante o enfrentamento da pandemia, pois forneceram espaços para a população praticar atividade física e socialização. E dessa forma contribuir na redução do estresse e ansiedade, melhorando então a saúde física e mental dos usuários dos parques. Com isso, torna-se necessário que aconteça um planejamento para adequar e melhorar as funções dos parques das cidades durante pandemias como essa, para que facilite as visitas seguras e evitar que a população fique privada de ir à áreas de lazer e assim comprometendo a sua saúde física e mental, uma sugestão seria realizar pesquisas com os frequentadores dessas áreas verdes urbanas, com objetivo de saber a opinião do público que utiliza esse ambiente, como forma de possíveis melhorias desses ambientes em épocas como essa futuramente.

\section{Referências}

Barcellos, V. Q. (2000). Os parques: velhas ideias e novas experiências. Paisagem ambiente ensaios, 13, 49-71.

Brasil. (2000). Ministério do Meio Ambiente (2000, 19 de julho). Lei n. 9.985, de 18 de Julho de 2000. Sistema Nacional de Unidades de Conservação da Natureza - SNUC, Diário Oficial da República Federativa do Brasil. http://www.planalto.gov.br/ccivil_03/leis/19985.htm

Carneiro, A. R. \& Mesquita, L. de B. (2000). Espaços livres do Recife. Centro de Estudos Avançados da Conservação Integrada. Prefeitura da cidade do Recife/UFPE. 
Cunha, M. V. P. de O., Gomes, E. G. S., Fernandes, J. C. F. de A. (20016). A relação entre o ambiente e o usuário - o mapa comportamental como instrumento de definição de rota acessível. VI Encontro Nacional de Ergonomia do Ambiente Construído \& VII Seminário Brasileiro de Acessibilidade Integral, 2, (7).

Gascon, M., Sánchez-Benavides, G., Dadvand, P., Martínez, D., Gramunt, N., Gotsens, X. \& Nieuwenhuijsen, M. (2018). Long-term exposure to residential green and blue spaces and anxiety and depression in adults: A cross-sectional study. Environmental Research, 162, 231-239.

Kamara, S., Walder, A., Duncan, J., Kabbedijk, A., Hughes, P. \& Muana, A. (2017). Cuidados de saúde mental durante o surto da doença do vírus Ebola em Serra Leoa. Organização Mundial da Saúde, 95, (842).

Kothencz, G. \& Blaschke, T. (2017). Urban parks: Visitors' perceptions versus spatial indicators. Land use policy, 64, $233-244$.

Liberalino, C. C. (2011). Praça: lugar de lazer. Relações entre características ambientais e comportamentais na Praça Kalina Maia - Natal/RN, [Dissertação de Mestrado, Universidade Federal do Rio Grande do Norte].

Macedo, S. S. \& Sakata, F. G. S. (2010). Parques urbanos no Brasil. (3a ed.), Editora da Universidade de São Paulo.

Paula, D. (2017). Usos e desusos de parques urbanos contemporâneos: estudo de caso do Parque da Cidade-Serra/ES [Dissertação de Mestrado, Universidade Federal do Espírito Santos].

Paula, D. de \& Caser, K. do C. (2020). Usos e desusos dos parques urbanos: Um panorama sobre suas origens, tipos e usos. Revista Nacional de Gerenciamento de Cidades, 8(63), 33-53.

Pimentel, A. do S. G., SILVA, M. de N. R. M. de O. (2020). Saúde psíquica em tempos de Corona vírus. Research, Society and Development, 9 (7), e11973602.

Rheingantz, P. A., Azevedo, G. A., Brasileiro, A., Alcantra, D. de. \& Queiroz, M. (2009). Observando a qualidade do lugar: procedimentos para a avaliação pós-ocupação. PROARQ.

Ribeiro, A. I., Tavres, C., Guttentag, A. \& Barros, H. (2019). Association between neighbourhood green space and biological markers in schoolaged children. Findings from the Generation XXI birth cohort. Environment international, 132, (105070).

Silva, L. C. da., Nascimento, D. S. do., Sales, M. R. \& Souza, R. G. (2021). Pandemia e lazer: os reflexos da pandemia nos cotidianos de lazer das periferias urbanas. Revista Augustus, 53 (26), 125-146.

Szeremeta, B. \& Zannin, P. H. T. (2013). A importância dos parques urbanos e áreas verdes na promoção da qualidade de vida em cidades. Revista Ra'e Ga, $29,177-193$.

Tendais, I. \& Ribeiro, A. I. (2020). Espaços verdes urbanos e saúde mental durante o confinamento causado pela COVID-19. Finisterra, 115, 183-188.

Triguero-Mas, M., Donaire-Gonzalez, D., Seto, E., Valetín, A., Martínez, D., Smith, G. \& Nieuweenhuijsen, M. J. (2017). Natural outdoor environments and mental health: stress as a possible mechanism. Environmental Research, 159, 629-638.

Ventura, A. C., Silva, T. S. \& Carvalho, C. A. (2021). Estratégias de resiliência e território: atuação de salvador no enfrentamento a pandemias. Revista interdisciplinar de gestão social, 10, 107-120.

Xie, J., Luo, S., Furuya, K. \& Sun, D. (2020). Urban Parks as Green Buffers During the COVID-19 Pandemic. Sustainability,12, (6751), 1-17.

Ximenes, D. S. S., Maglio, I. C. \& Franco, M. de A. R. (2020). A interferência verde nos espaços públicos como elemento de resiliência socioambiental póspandemia. Labor \& Engenho, 14, 1-16. 